OPEN ACCESS

Edited by:

Luisa Ricciardi,

University of Messina, Italy

Reviewed by:

Simon Blank,

Technical University of Munich and

Helmholtz Center Munich, Germany

*Correspondence:

Enrico Heffler

enrico.heffler@hunimed.eu

Specialty section:

This article was submitted to Drug, Venom \& Anaphylaxis,

a section of the journal

Frontiers in Allergy

Received: 13 January 2022

Accepted: 24 January 2022

Published: 16 February 2022

Citation:

Incorvaia C, Ridolo E, Mauro M.

Pucciarini F, Heffler E and

Canonica GW (2022) Venom Immunotherapy and Aeroallergen

Immunotherapy: How Do Their

Outcomes Differ?

Front. Allergy 3:854080

doi: $10.3389 /$ falgy.2022.854080

\section{Venom Immunotherapy and Aeroallergen Immunotherapy: How Do Their Outcomes Differ?}

\author{
Cristoforo Incorvaia ${ }^{1}$, Erminia Ridolo ${ }^{1}$, Marina Mauro ${ }^{2}$, Francesco Pucciarini ${ }^{1}$, \\ Enrico Heffler ${ }^{3,4 *}$ and Giorgio Walter Canonica ${ }^{3,4}$
}

${ }^{1}$ Allergy and Clinical Immunology, Medicine and Surgery Department, University of Parma, Parma, Italy, ${ }^{2}$ Allergy Unit, S. Anna Hospital, Como, Italy, ${ }^{3}$ Department of Biomedical Sciences, Humanitas University, Pieve Emanuele, Italy, ${ }^{4}$ Personalized Medicine, Asthma and Allergy, IRCCS Humanitas Research Hospital, Rozzano, Italy

Allergen immunotherapy (AIT) and venom immunotherapy (VIT) are meant to work on the causes of allergies, respectively, to respiratory allergens and Hymenoptera venom, inducing tolerance to the allergens and modifying the natural history of allergy. Both types of immunotherapies have evidence of efficacy, but actually they present wide differences in both effectiveness and safety. Indeed, as far as the effectiveness of VIT is concerned, if the protection against fatal reactions to stings is considered as the primary objective, more than 40 years of clinical practice demonstrate complete success. The clinical success of AIT is measurable on the basis of reduction or disappearance of allergic symptoms. The difference between the two treatments is even higher as regards safety: AIT has been concerned in the past by a series of fatal reactions caused, which underwent a progressive decrease when it was understood that they were related to the presence of uncontrolled asthma. However, fatal reactions related to failure to recognize the presence of risk factors or administration errors are still reported. Similarly to what has been observed for efficacy, VIT has never been affected by fatal reactions to the administration of venom, and the most important risk of anaphylaxis, which is the concomitance of mastocytosis, is now identified by measuring its marker serum tryptase. To date, mechanisms of hypersensitivity reactions that differentiate respiratory allergy from Hymenoptera venom allergy have not been successfully demonstrated. We have examined the past and present literature in order to propose reasonable hypotheses about the mechanisms actually involved.

Keywords: venom immunotherapy, Hymenoptera, anaphylaxis, prevention, allergy

\section{INTRODUCTION}

Immunotherapy of allergic diseases is currently applied on respiratory allergy, insect venom allergy and food allergy with the aim to induce immunologic tolerance to the causative agent. While immunotherapy for food allergy was only recently approved by FDA, limited to the treatment of peanut allergy (1), those for respiratory allergens and Hymenoptera venom allergy were introduced many years ago, particularly in 1915 (2) and 1930 (3), respectively, when scientific knowledge on pathophysiology of allergy was unknown. Despite its empiric nature, some positive response to the injective administration of grass pollen extracts was observed, paving the way for the progressive 
development of scientific facts and treatment efficacy. Immunotherapy for insect venom allergy debuted in 1930 (4), but due to the unique natural history of this kind of allergy, which foresees that an initial reaction can be followed by tolerance to subsequent stings of the stinging culprit insect (2), it was believed for 40 years that whole body insect therapy was effective (3). In 1978, a controlled trial comparing whole body treatment to placebo and to insect venom demonstrated the overlap of whole body and placebo, while Hymenoptera venom was extremely effective (4). It is of interest that instead the whole body of fire ant is provably effective (5), but the high disproportion of the ratio between body size and quantity of venom in Hymenoptera and in fire ant can justify this. Immunotherapy with aeroallergens and whit Hymenoptera venom share the effect of not only acting on symptoms, as drugs do, but also on changing the natural history of allergy by modifying its mechanisms and inducing tolerance to the causative allergens (6). Indeed, although some differences between the two treatments are striking, as far as we know there is no literature that has analyzed and compared them. We have dedicated this argument to a comparison of all the divergent aspects between immunotherapy for aeroallergens and immunotherapy for Hymenoptera venom.

\section{COMPARING THE EFFECTIVENESS}

Both types of immunotherapy are acknowledged as effective and disease modifying by the respective consensus documents and guidelines $(7,8)$. However, their type and degree of effectiveness are not the same (Table 1). Actually, considering the primary objectives, venom immunotherapy (VIT) is aimed at preventing fatal or life-threatening reactions to stings, while allergen immunotherapy (AIT) aims to reduce or abolish allergy symptoms by inducing tolerance. The ability of VIT to prevent fatal reactions to stings must be considered complete, since none has ever been reported in more than 40 years of practice. Furthermore, it has been shown that in patients not fully protected from stings by the generally recommended $100 \mathrm{mcg}$ it is always possible to identify in individual patients a higher dose achieving protection (9). As far as the risk of severe reactions after VIT stopping is concerned, the critical factor is represented by the concomitance of mastocytosis, first reported in 1997, when two patients with mastocysosis had fatal reactions to re-stings from yellow jacket after VIT was stopped based on reaching the recommended duration (10). Now we know that systemic mastocytosis and senior age are major risk factors for severe reactions to stings, which strengthen the indication for VIT. High serum tryptase elevation and mast cell clonality are the most important indicators, but also absence of urticaria/angioedema during sting-induced anaphylaxis may predict a severe reaction (11). As for the duration, it is recommended that it be unlimited (8).

Unlike VIT, which is virtually always effective, the effectiveness of AIT, as well as that of symptomatic drugs, is not predictable in individual patients. In a retrospective study on 1,624 patients suffering from allergic rhinitis (AR) who were treated with AIT and 1,519 matched patients were treated with only symptomatic therapy, symptoms, medications scores and quality of life related to allergic condition before and after treatment were assessed and investigated by cluster analysis. The results showed that AIT was significantly more effective than symptomatic therapy in the treatment of AR, particularly in presence of an association between a better response to AIT and a short-term history of AR with concomitant grass pollen allergy and/or dust mite allergy. Differently, patients with coexisting atopic dermatitis, polysensitization, allergies to cats, Alternaria or mugwort and protracted duration of allergic disease apparently had an unsatisfactory response to AIT (12). Recent studies have added knowledge to the issue, focusing on the most common cause of allergy, namely house dust mites. A prospective study was dedicated to methods for predicting the efficacy of subcutaneous immunotherapy, being observed that the overall efficacy rate at the end of the second year of treatment was $67.4 \%$, and that efficacy of AIT at months 4, 6, 12, and 18 was powerfully associated with efficacy at month 24 . In particular, early efficacy (month 4) predicted efficacy at the second year, suggesting the likelihood to determine the need for long-term treatment (13). The other prospective study was aimed at investigating in 154 patients with dust mite-induced AR who had low response to sublingual immunotherapy (SLIT. According to results, 6 months might be a critical time point for assessment of efficacy and dosage adjustment in patients undergoing SLIT, that because of a much higher safety than the subcutaneous route allows a dosage increase in patients with low response, which can may enhance the effectiveness of treatment (14). Another important aspect concerns the qualitative differences between the products of different manufactures. Actually, the need for new products to adhere to requirements from regulatory agencies concerning the quality control (including measurement of protein content, total allergenic activity, and major allergen content) as well as manufacturing is resulting in a major effect on the quality of products (15).

\section{COMPARING THE SAFETY}

Likewise for effectiveness, the advantage of VIT over AIT is apparent. In fact, no fatal reactions to VIT have ever been reported (16), although during the buildup phase systemic reactions may occur that hinder the achievement of the maintenance dose, which is recommended in $100 \mathrm{mcg}$ in common patients and $200 \mathrm{mcg}$ in patients exposed to frequent stings, such as beekeepers, or with mastocytosis. This obstacle can be overcome by pharmacological prevention with antihistamines (17) or, in the case of more severe reactions, with omalizumab (18).

Instead, AIT fatalities have been a very serious problem in the past, which today has been significantly reduced but not completely abolished. The origin of the problem dates back to the 1980s, when the introduction of allergen extracts with high biological potency was associated with a series of fatal reactions that imposed limitations, and in some countries abandonment, of AIT $(19,20)$. The essential understanding that the dominant cause of mortality was injecting the allergen extract to patients with uncontrolled asthma has resulted in a dramatical reduction of the number of fatal reactions, although a slight increase 
TABLE 1 | Features of AIT and VIT.

\begin{tabular}{|c|c|}
\hline Aeroallergen immunotherapy & Venom immunotherapy \\
\hline \multicolumn{2}{|c|}{ Indication and aim of the treatment } \\
\hline $\begin{array}{l}\text { In patients with allergic rhinitis and asthma, with the aim to reduce or abolish } \\
\text { allergic symptoms. }\end{array}$ & $\begin{array}{l}\text { In patients with hymenoptera venom allergy, with the aim to prevent fatal or } \\
\text { life-threatening reactions to stings. }\end{array}$ \\
\hline \multicolumn{2}{|c|}{ Route of administration } \\
\hline SCIT: subcutaneous injections & SCIT: subcutaneous injections \\
\hline \multicolumn{2}{|c|}{ Dosage } \\
\hline Different dosage depending on the allergen and the administration route. & $\begin{array}{l}\text { Standardized induction phase (rush or ultra-rush), then maintenance phase } 100 \\
\mathrm{mcg} / \mathrm{ml} \text { every month for the first } 3 \text { years and then once every } 2 \text { months. }\end{array}$ \\
\hline \multicolumn{2}{|c|}{ Treatment duration } \\
\hline $3-5$ years & $\begin{array}{l}5 \text { years } \\
\text { Lifelong therapy in selected patients (history of severe anaphylaxis, clonal mast } \\
\text { cell disorders. }\end{array}$ \\
\hline \multicolumn{2}{|c|}{ 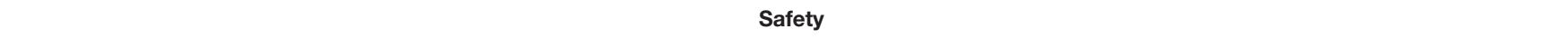 } \\
\hline $\begin{array}{l}\text { Reported cases of fatal reactions in the past years, mainly related to SCIT during } \\
\text { the induction phase with rush scheme, in patients with uncontrolled asthma, } \\
\text { history of previous systemic reactions. }\end{array}$ & $\begin{array}{l}\text { Cases of systemic reactions during the induction phase. } \\
\text { No reports of fatal reactions. }\end{array}$ \\
\hline \multicolumn{2}{|c|}{ Efficacy } \\
\hline Moderate efficacy rate (60-80\%) & $\begin{array}{l}\text { High efficacy (>90\%) } \\
\text { Patients still reacting after sting challenges can benefit from increased } \\
\text { venom doses. }\end{array}$ \\
\hline \multicolumn{2}{|c|}{ Predictors of efficacy } \\
\hline $\begin{array}{l}\text { Disease history: higher efficacy in short term history of AR. } \\
\text { Type of allergen: higher efficacy in grass pollen and dust mite allergy, lower in } \\
\text { allergy to Alternaria, cat or mugwort. } \\
\text { Polysensitization and atopic dermatitis are related to lower efficacy. } \\
\text { Evaluation of efficacy after the first months ( } 4-6 \text { months) of therapy is a good } \\
\text { predictor of overall efficacy after } 24-36 \text { months of AIT. }\end{array}$ & sCD30/TNFRSF8 sTNF-R1 \\
\hline
\end{tabular}

has been observed in recent years (21) suggesting the need for physicians and healthcare professionals to maintain a high level of attention.

\section{CAN REASONABLE HYPOTHESIS BE PROPOSED TO EXPLAIN THE UNSETTLED DIFFERENCES BETWEEN VIT AND AIT?}

The lesson learned from the large reduction in fatal reactions to AIT achieved by ensuring that at the time of the allergen injection the patient did not have uncontrolled asthma offers us an interpretative key to understand the mechanisms underlying severe reactions to treatment. The mechanisms of action of AIT include the induction of very early desensitization of mast cells and basophils, generation of regulatory $\mathrm{T}$ and $\mathrm{B}$ regulatory cell responses, regulation of $\operatorname{IgE}$ and $\operatorname{IgG} 4$, reduction of eosinophils and mast cells in mucosal allergic tissues, and decreases in the activity of basophils in circulation. The key event in inducing tolerance to the administered allergen is the skewing of allergenspecific effector $\mathrm{T}$ and effector $\mathrm{B}$ cells to a regulatory phenotype and normal immune response to allergens (22). Regarding VIT, it has been found that during ultra-rush schedule $\mathrm{T}$ helper type 2 (Th2)-to-Th1 switch occurs, in parallel with natural and acquired regulatory $\mathrm{T}$ cell increase. These events occur earlier and at higher level in less severe subjects, suggesting that VIT tolerance induction is easier to achieve in these patients (23). However, it is imperative to consider the different exposure to allergens in the two sensitization models. In fact, in allergy to inhalant agents, prolonged or even perennial exposure (as occurs with indoor allergens) is mirrored in persistent inflammation, while sporadic exposure related to Hymenoptera stings can result in initial inflammation that relapses with the absence of further stings. In 1994 a study evaluated the importance of the interval between two consecutive stings in influencing the development of venom allergy. The results from 120 allergic patients who experienced a first-time systemic reaction to a sting and 100 controls showed a significant difference in sting-interval distribution indicating that in $60 \%$ of allergic patients the sting causing the systemic reaction had been preceded by another, completely tolerated sting not more than 2 months before (24). An assessment of the degree of inflammation was not performed, but it is reasonable to assume that it did not persist beyond the 2 month limit. In contrast, the effects of venom change significantly in subjects exposed to very frequent stings, such as beekeepers. Actually, though the absence of fatal reactions remains, systemic reactions are much more common to bee stings than to vespid stings, as found in a systematic review that reported an incidence of $25.1 \%$ for honeybee venom vs. $5.8 \%$ for vespid venom $(p<0.0001)(25)$.

A recent study including 21 patients allergic to wasp and/or honey bee venom and 42 healthy participants was aimed to 
discover new biomarkers of Hymenoptera venom allergy in a group of inflammation factors using multi-marker Bioplex panel and adding the adoption of a novel methodology based on Luminex/xMAP allowed the concurrent determination of serum levels of 37 different inflammatory types. By univariate multivariate statistics, soluble CD30/tumor necrosis factor receptor superfamily, member 8 (sCD30/TNFRSF8), and the soluble tumor necrosis factor receptor 1 (sTNF-R1) cold be considered as effective prognostic factors, their circulating levels being significantly decreased in allergic patients According to the authors, the results shed new light on the allergic inflammatory response to Hymenoptera venom and may contribute to modification and improvement of the diagnostic and monitoring methods (26). However, studies on larger patients' population are needed to confirm the possible usefulness in clinical practice. Finally, a new approach to prevent life-threatening reactions, which is particularly useful for patients who are candidates

\section{REFERENCES}

1. Patrawala M, Shih J, Lee G, Vickery B. Peanut oral immunotherapy: a current perspective. Curr Allergy Asthma Rep. (2020) 20:14. doi: 10.1007/s11882-020-00908-6

2. Golden DB, Marsh DG, Freidhoff LR, Kwiterovich KA, Addison B, Kagey-Sobotka et al. Natural history of Hymenoptera venom sensitivity in adults. J Allergy Clin Immunol. (1997) 100(Pt. 1):760-6. doi: 10.1016/S0091-6749(97)70270-7

3. Pence H. Stinging insect allergy. Prim Care. (1979) 6:58796. doi: 10.1016/S0095-4543(21)00816-2

4. Hunt KJ, Valentine MD, Sobotka AK, Benton AW, Amodio FJ, Lichtenstein LM. A controlled trial of immunotherapy in insect hypersensitivity. $N$ Engl J Med. (1978) 299:157-61. doi: 10.1056/NEJM197807272990401

5. Freeman TM, Hylander R, Ortiz A, Martin ME. Imported fire ant immunotherapy: effectiveness of whole body extracts. J Allergy Clin Immunol. (1992) 90:210-5. doi: 10.1016/0091-6749(92)90073-B

6. Breiteneder H, Diamant Z, Eiwegger T, Fokkens WJ, Traidl-Hoffmann C, et al. Future research trends in understanding the mechanisms underlying allergic diseases for improved patient care. Allergy. (2019) 74:2293311. doi: 10.1111/all.13851

7. Jutel M, Agache I, Bonini S, Burks AW, Calderon M, Canonica W, et al. International consensus on allergy immunotherapy. J Allergy Clin Immunol. (2015) 136:556-68. doi: 10.1016/j.jaci.2015.04.047

8. Golden DBK. Insect sting allergy: new guidelines from the European and USA consensus groups: algorithms and recommendations. Curr Opin Allergy Clin Immunol. (2019) 19:456-61. doi: 10.1097/ACI.0000000000000570

9. Ruëff F, Wenderoth A, Przybilla B. Patients still reacting to a sting challenge while receiving conventional Hymenoptera venom immunotherapy are protected by increased venom doses. J Allergy Clin Immunol. (2001) 108:102732. doi: 10.1067/mai.2001.119154

10. Oude Elberink JN, de Monchy JD, Kors JW, van Doormaal J, Duboise AE. Fatal anaphylaxis after a yellow jacket sting, despite venom immunotherapy, in two patients with mastocytosis. J Allergy Clin Immunol. (1997) 99(Pt. 1):153-4. doi: 10.1016/S0091-6749(97)70314-2

11. Stoevesandt J, Sturm GJ, Bonadonna P, Oude Elberink JNG, Trautmann A. Risk factors and indicators of severe systemic insect sting reactions. Allergy. (2020) 75:535-45. doi: 10.1111/all.13945

12. Jakalski M, Bozek A, Canonica GW. Responders and nonresponders to pharmacotherapy and allergen immunotherapy. Hum Vaccines Immunother. (2019) 15:2896-902. doi: 10.1080/21645515.2019.1614397

13. Liu Z, Lu H, Feng X, Li Hu, Wang J, Yu H. Predictive methods for efficacy of house dust mite subcutaneous immunotherapy in allergic rhinitis patients. Forum Allergy Rinol. (2020) 10:314. doi: 10.1002/alr.22508 for AIT but with a history of asthma exacerbations, can be represented by the identification of the responsible mechanisms and their blocking by means of specific biologics, which are the therapeutic innovation of greatest interest (27). Once the cytokine profile has been identified in the individual patient, the specific biologic could be used, as done with omalizumab for patients with repeated systemic reactions to VIT (18) in the initial phase of AIT, to be then suspended when tolerance to treatment is apparent.

\section{AUTHOR CONTRIBUTIONS}

CI, ER, MM, and GC contributed in ideating the review concept, writing the article, and critically revising the final manuscript. FP and $\mathrm{EH}$ contributed in writing the article and critically revising the final manuscript. All authors have read and approved the final version of the manuscript.
14. Gao Y, Lin X, Ma J, Wei X, Wang Q, Wang M. Enhanced efficacy of dust mite sublingual immunotherapy in low-response allergic rhinitis patients after dose increment at 6 months: a prospective study. Int Arch Allergy Immunol. (2020) 181:311-19. doi: 10.1159/000505746

15. Englert L, Mahler V, Bonertz A. Regulatory requirements for the quality of allergen products for allergen immunotherapy of food allergy. Curr Allergy Asthma Rep. (2021) 21:32. doi: 10.1007/ s11882-021-01008-9

16. Turner PJ, Campbell DE, Motosue MS, Campbell RL. Global trends in anaphylaxis epidemiology and clinical implications. J Allergy Clin Immunol Pract. (2020) 8:1169-76. doi: 10.1016/j.jaip.2019.11.027

17. Brockow K, Kiehn M, Riethmüller C, Vieluf D, Berger J, Ring J. Effficacy of antihistamine pretreatment in the prevention of adverse reactions to Hymenoptera immunotherapy: a prospective, randomized, placebo-controlled trial. J Allergy Clin Immunol. (1997) 100:458-63. doi: 10.1016/S0091-6749(97)70135-0

18. Stretz E, Oppel EM, Räwer HC, Chatelain R, Mastnik S, Przybilla B, et al. Overcoming severe adverse reactions to venom immunotherapy using antiIgE antibodies in combination with a high maintenance dose. Clin Exp Allergy. (2017) 47:1631-9. doi: 10.1111/cea.12997

19. Reid MJ, Lockey RF, Turkeltaub PC, Platts-Mills TA. Survey of fatalities from skin testing and immunotherapy 1985-1989. J Allergy Clin Immunol. (1993) 92:6-15. doi: 10.1016/0091-6749(93)90030-J

20. Frew AJ. Injection immunotherapy. British Society for Allergy and Clinical Immunology Working Party. BMJ. (1993) 307:91923. doi: 10.1136/bmj.307.6909.919

21. Epstein TG, Murphy-Berendts K, Liss GM, Bernstein DI. Risk factors for fatal and nonfatal reactions to immunotherapy (2008-2018): postinjection monitoring and severe asthma. Ann Allergy Asthma Immunol. (2021) 127:6469. doi: 10.1016/j.anai.2021.03.011

22. Akdis M, Akdis CA. Mechanisms of allergen-specific immunotherapy: multiple suppressor factors at work in immune tolerance to allergens. J Allergy Clin Immunol. (2014) 133:621-31. doi: 10.1016/ j.jaci.2013.12.1088

23. Mamessier E, Birnbaum J, Dupuy P, Vervloet D, Magnan. A Ultra-rush venom immunotherapy induces differential $\mathrm{T}$ cell activation and regulatory patterns according to the severity of allergy. Clin Exp Allergy. (2006) 36:70413. doi: 10.1111/j.1365-2222.2006.02487.x

24. Pucci S, Antonicelli L, Bilò MB, Garritani MS, Bonifazi F. Shortness of interval between two stings as risk factor for developing Hymenoptera venom allergy. Allergy. (1994) 49:894-6. doi: 10.1111/ j.1398-9995.1994.tb00796.x

25. Incorvaia C, Frati F, Dell'Albani I, Robino A, Cattaneo E, Mauro M, et al. Safety of hymenoptera venom immunotherapy: a systematic review. 
Expert Opin Pharmacother. (2011) 12:2527-32. doi: 10.1517/ 14656566.2011.616494

26. Pack K, Matysiak J, Matuszewska E, Breborowicz A, Kycler Z, Matysiak J. New biomarkers of Hymenoptera venom allergy in a group of inflammation factors. Int J Environ Res Public Health. (2021) 18:4011. doi: 10.3390/ ijerph18084011

27. Wu AC, Busse WW. Biologic therapy in allergy practice: a new era in treatment has begun. J Allergy Clin Immunol Pract. (2021) 9:111820. doi: 10.1016/j.jaip.2020.12.036

Conflict of Interest: The authors declare that the research was conducted in the absence of any commercial or financial relationships that could be construed as a potential conflict of interest.
Publisher's Note: All claims expressed in this article are solely those of the authors and do not necessarily represent those of their affiliated organizations, or those of the publisher, the editors and the reviewers. Any product that may be evaluated in this article, or claim that may be made by its manufacturer, is not guaranteed or endorsed by the publisher.

Copyright (๑) 2022 Incorvaia, Ridolo, Mauro, Pucciarini, Heffler and Canonica. This is an open-access article distributed under the terms of the Creative Commons Attribution License (CC BY). The use, distribution or reproduction in other forums is permitted, provided the original author $(s)$ and the copyright owner(s) are credited and that the original publication in this journal is cited, in accordance with accepted academic practice. No use, distribution or reproduction is permitted which does not comply with these terms. 